\title{
A Study of the Bond Behavior of FRP Bars in MPC Seawater
}

\section{Concrete}

\author{
Wen Sun ${ }^{\mathrm{a}, \mathrm{b}}$, Yu Zheng ${ }^{\mathrm{b}, *}$, Linzhu Zhou ${ }^{\mathrm{b}, \mathrm{c}}$, Jiapeng Song ${ }^{\mathrm{a}}$, Yun Bai ${ }^{\mathrm{a}^{* *}}$, \\ ${ }^{a}$ Department of Civil, Environmental \& Geomatic Engineering, University College London, UK \\ ${ }^{b}$ School of Environment and Civil Engineering, Dongguan University of Technology, Dongguan 523080 \\ ${ }^{c}$ Key Laboratory of Coastal and Offshore Engineering, Dalian University of Technology, Dalian 116024, China \\ * Correspondence: zhengy@dgut.edu.cn \\ **Correspondence: yun.bai@ucl.ac.uk
}

\section{HIGHLIGHT:}

- The bond behavior of the FRP bars in MPC concrete was studied and compared with that of in PC concrete.

- $\quad$ MPC can enhance the bond with FRP bars.

- Using seawater as mixing water in MPC showed a positive effect on the bond strength of MPC-FRP bar.

- The mBPE model and CMR model can be used to predict the bond behavior of the MPC-GFRP bar.

\begin{abstract}
:
Using magnesium potassium phosphate cement (MPC) and fiber-reinforced polymer (FRP) bar to produce reinforced concrete can overcome the durability problems facing conventional steel reinforced PC concrete. In addition, FRP bar reinforced MPC concrete can also mitigate the $\mathrm{CO}_{2}$ emission issues caused by Portland cement $(\mathrm{PC})$ production and the shortage of natural resources such as virgin aggregates and freshwater. This paper, therefore, is aimed at investigating the bond behavior the FRP bars in MPC seawater concrete. The direct pull out tests were conducted with a steel bar, BFRP bar, and GFRP bar embedded into different concretes. The effects of reinforcing bars, type of concrete and mixing water on the bond behavior of FRP and steel bars were investigated and discussed. The results showed that the MPC concrete increases the bond strength of BFRP and GFRP bars by $51.06 \%$ and $24.42 \%$, respectively, compared with that in PC concrete. Using seawater in MPC concrete can enhance the bond strength of GFRP bar by $13.75 \%$. The damage interface of the FRP bar -MPC is more severe than that of PC with a complete rupture of the FRP ribs and peeling-off of the resin compared to that in steel reinforced MPC specimens. Moreover, the bond stress-slip models were developed to describe the bond behavior of MPC-FRP specimen, and the analytical results match well with the experimental data. In conclusion, the FRP bars showed better bond behavior in the MPC seawater concrete than that in the PC counterparts.
\end{abstract}


Keywords: Bond behavior; Bond strength; FRP; Magnesium potassium phosphate cement; Seawater

\section{Introduction}

Considerable amounts of freshwater has been consumed every year by the construction industry to produce concrete, and this has inevitably contributed to the shortage of freshwater resources (Xiao et al., 2017). Thus, it is more economical and sustainable to use seawater to manufacture concrete in coastal regions where seawater is readily and abundantly available. However, traditional steel reinforced concrete (RC) structures suffer durability issues if seawater is adopted. This is because chloride ions in seawater can cause the corrosion of reinforcing steel and, hence, limits its applications. To solve this problem, fiber reinforced polymer (FFP) bar is normally used to replace reinforcing steel in reinforced seawater concrete, and this practice has now been widely accepted by several countries, such as Japan, Canada and America (Maranan et al., 2015). Compared to steel bar, FRP bar has several advantages, including high tensile strength, lightweight, low thermal conductivity and good corrosion resistance (S érgio et al., 2020). Although the initial cost of using FRP bar is higher than that of steel bar, the service life of FRP-RC structure is longer, and the maintenance cost is also lower than that of steel-RC structure. Therefore, the life-cycle cost of FRP-RC structures is potentially lower than that of conventional RC structures (Maranan et al., 2015). As is well reported, the bond behavior of FRP bar in concrete structures is a critical parameter influencing the safety and performance of FRP reinforced concrete structures. However, many factors, such as concrete strength, mixing water, FRP bar type, surface treatment and bar diameter, can potentially affect the bond behavior of the FRP bar (Baena et al., 2009; Sérgio et al.,2020). For example, Baena et al., (2009) studied the effects of rebar surface, fiber type, rebar diameter and concrete strength on the bond behavior of carbon fiber reinforced polymer (CFRP) and glass fiber reinforced polymer (GFRP) bars. It was found that increasing concrete strength resulted in higher bond strengths and varied failure mode in the test. Additionally, the bond mechanism and the bond strength were also influenced by the surface treatment of FRP bar. Furthermore, the $\mathrm{pH}$ and salt solutions were also found to be able to influence the bond behavior. For instance, Guo et al., (2018) investigated the durability of FRP bar in simulated seawater and sea sand concrete (SWSSC) and their results showed that the degradation of resin and fibers were more severe in high alkaline concrete solutions. However, among the different FRP bars investigated, the CFRP bar showed better corrosion resistance in high alkaline solution than the basalt fiber reinforced polymer (BFRP) and GFRP bars. On the other hand, Dong et al., (2018) studied the long-term bond behavior of BFRP and steel-fiber reinforced polymer composite bars (SFCB) in concrete when they were subjected to a wet-dry cycle by seawater at $40^{\circ} \mathrm{C}$ and immersion in seawater at $50^{\circ} \mathrm{C}$ for nine months. The test results showed that the alkaline environment of concrete promoted the debonding of fiber-resin in FRP, leading to the reduction of bond strength. Moreover, the bond degradation was even worsened in the seawater immersion environment. In contrast, Sérgio et al., (2020) evaluated the GFRP bond behavior in seawater concrete and demonstrated that seawater had no severe effects on bond behavior of GFRP bar. On the other hand, it was reported by Adel et al. (2018) that when seawater was applied to Portland cement (PC), the 7-day compressive strength was slightly increased, but the reduction of 28-day compressive strength was observed. It is, thus, anticipated that the 
decrease in concrete strength may also lead to a reduction in the bond strength.

One way to solve the degradation of FRP bar due to high alkaline condition in PC-based concrete is to replace PC with low-pH cements. Among several potential systems, magnesium potassium phosphate cement (MPC) has been considered as a promising alternative. MPC is a low-pH cementitious material reacted through a neutralization reaction between dead burnt magnesia and phosphate, deriving from the 19th century (Liu and Chen, 2016). As this reaction is too fast to be employed in construction, retarders such as boric acid or borax are often used to prolong the setting time (Yang et al., 2017). Normally, two kinds of phosphate can be used to formulate MPC, including ammonium dihydrogen phosphate (ADP) and potassium dihydrogen phosphate (KDP). However, the unpleasant odor produced by ASD, resulting in an uncomfortable working environment, limits its application. On the contrary, the low solubility and smaller dissociation constant of KDP make it favorable to control the reaction of MPC. However, in some cases, considering the cost, ADP is preferred (Fan Chen B 2015; Ma H et al., 2014). The reactions of MPC with these two types of phosphates are shown, respectively, below.

$$
\begin{aligned}
& \mathrm{MgO}(s)+\mathrm{NH}_{4} \mathrm{H}_{2} \mathrm{PO}_{4}(s)+5 \mathrm{H}_{2} \mathrm{O}(l) \longrightarrow \mathrm{MgNH}_{4} \mathrm{PO}_{4} \cdot 6 \mathrm{H}_{2} \mathrm{O}(s) \\
& \mathrm{MgO}(s)+\mathrm{KH}_{2} \mathrm{PO}_{4}(s)+5 \mathrm{H}_{2} \mathrm{O}(l) \longrightarrow \mathrm{MgKPO}_{4} \cdot 6 \mathrm{H}_{2} \mathrm{O}(s)
\end{aligned}
$$

The previous research shows that MPC has many superior properties over PC concrete, such as high early hydration and strength, quick setting time, good bond strength with old concrete, high volume stability and good resistance to abrasion and frost (Li and Chen, 2013; Liu and Chen, 2016). Compared with PC, MPC is more environmentally friendly because of its low $\mathrm{CO}_{2}$ emission and higher $\mathrm{CO}_{2}$ uptake nature (Liu and Chen, 2016). More importantly, MPC has a low $\mathrm{pH}$ value, which may benefit the durability of FRP bars embedded in concrete. Additionally, MPC has a lower water demand than PC which means less water is needed for manufacturing concrete with the same consistence as PC. In addition, it has been reported that the weak alkaline environment of seawater could also benefit the hydration of MPC, leading to a higher compressive strength (Yang et al., 2017).

As presented in the above literature review, MPC could be a potential alternative system to address the degradation of FRP in the high $\mathrm{pH}$ environment of PC concrete. Additionally, incorporation of seawater into MPC could also benefit its chemical reaction. Therefore, MPC may offer a great potential for manufacturing FRP bar reinforced structural seawater concrete. However, up to date, the bond behavior of FRP bars in MPC-based seawater concrete is still unknown which may hinder its potential industrial application. The aim of this study is, thus, mainly focused on investigating the bond behavior between FRP bars and MPC concrete. Seawater, instead of freshwater, was used in the experiment to identify its influence on this innovative concrete system. The bond behavior of steel bar, BFRP bar, and GFRP bar in MPC concrete were evaluated by pullout tests. The results were also compared with the FRP bar reinforced PC system in order to identify the feasibility of its potential industrial application. Finally, the modified Bertero-Popov-Eligehausen (mBPE) model and the Cosenza-Manfredi-Realfonzo (CMR) model were developed to simulate the bond stress-slip curve of the MPC-FRP concrete specimen for further understanding of the bond behavior of FRP bars in MPC concrete.

\section{Experimental}




\subsection{Raw materials}

The MPC cement used in this study was a commercial product supplied by Guizhou Linmei Cailiao Co. Ltd., which was pre-blended with small amount of fly ash at a magnesium to phosphate ratio (M/P) of 3. A grade 42.5 Portland cement, manufactured by China Resources Cement (Dongguan) Ltd., was employed to formulate the PC concrete mix for comparison purpose. A river sand with the fineness modulus of 2.56 was used as fine aggregate and a gravel with $16 \mathrm{~mm}$ maximum size as coarse aggregate. The simulated/artificial seawater produced by following the ASTM 1141-98(2013) was adopted as mixing water, and its chemical composition is shown in Table 1. Three types of reinforcing bars were used to study the bond behavior, namely, BFRP, GFRP and steel bars. The diameters of all the bars were $13 \mathrm{~mm}$, and their surface was treated with spiral ribs. However, the widths and height of ribs are slightly different (as shown in Figure 1). For example, the spiral heights of GFRP and BFRP are $0.21 \mathrm{~mm}$ and $0.45 \mathrm{~mm}$, respectively. The tensile strength and elastic modulus of the reinforcing bars were tested in accordance with ACI 440.3R-04(2004). The properties of all these reinforcing bars are summarized and presented in Table 2 .

Table 1 Chemical composition of the artificial seawater

\begin{tabular}{lcccccc}
\hline Type of salt & $\mathrm{NaCl}$ & $\mathrm{MgCl}_{2}$ & $\mathrm{Na}_{2} \mathrm{SO}_{4}$ & $\mathrm{CaCl}_{2}$ & $\mathrm{KCl}$ & $\mathrm{NaHCO} 3$ \\
\hline $\begin{array}{l}\text { Concentration } \\
(\mathrm{g} / \mathrm{L})\end{array}$ & 24.53 & 5.2 & 4.09 & 1.16 & 0.695 & 0.201 \\
\hline
\end{tabular}
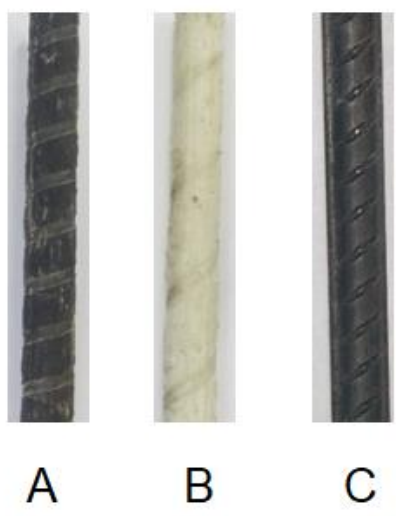

Figure 1 Photo of the reinforcing bars (A: BFRP bar; B: GFRP bar; C: steel bar)

Table 2 Properties of the reinforcing bars

\begin{tabular}{|c|c|c|c|c|c|}
\hline Bar type & $\begin{array}{l}\text { Diameter } \\
(\mathrm{mm})\end{array}$ & $\begin{array}{c}\text { Spiral height } \\
\text { (mm) }\end{array}$ & $\begin{array}{l}\text { Surface } \\
\text { treatment }\end{array}$ & $\begin{array}{c}\text { Tensile strength } \\
\text { (MPa) }\end{array}$ & $\begin{array}{c}\text { Elastic } \\
\text { modulus } \\
(\mathrm{GPa})\end{array}$ \\
\hline GFRP bar & 13 & 0.21 & $\begin{array}{l}\text { Sand-coating+ } \\
\text { Spiral ribs }\end{array}$ & 1126 & 54 \\
\hline BFRP bar & 12 & 0.45 & Spiral ribs & 1053 & 50 \\
\hline Steel bar & 13 & - & Crescent rib & 589 & 210 \\
\hline
\end{tabular}




\subsection{Mix proportion of MPC and PC concretes}

The MPC concrete was formulated with a water-to-cement ratio (W/C) of 0.17 in accordance with manufacturer's guidance. The mix proportion of the PC concrete was then established through trials in order to achieve similar workability and strength as those of the MPC concrete. The detailed mix proportions of the MPC and PC concretes are presented in Table 3.

Table 3 Proportions of MPC and PC concretes

\begin{tabular}{lccccc}
\hline Concrete Type & $\begin{array}{c}\text { Cement } \\
\left(\mathrm{kg} / \mathrm{cm}^{3}\right)\end{array}$ & $\begin{array}{c}\text { Gravel } \\
\left(\mathrm{kg} / \mathrm{cm}^{3}\right)\end{array}$ & $\begin{array}{c}\text { Sand } \\
\left(\mathrm{kg} / \mathrm{cm}^{3}\right)\end{array}$ & $\begin{array}{c}\text { Water } \\
\left(\mathrm{kg} / \mathrm{cm}^{3}\right)\end{array}$ & $\begin{array}{c}\text { w/c } \\
\left(\mathrm{kg} / \mathrm{cm}^{3}\right)\end{array}$ \\
\hline MPC concrete & 757 & 757 & 757 & 129 & 0.17 \\
PC concrete & 460 & 873.4 & 873.4 & 193.2 & 0.42 \\
\hline
\end{tabular}

Note: superplasticizer was added into PC concrete to achieve similar fluidity as MPC concrete

\subsection{Tests for assessing some basic properties of MPC and PC concretes}

The compressive strength and elastic modulus of concrete were tested in accordance with Chinese standard GB/T50081-2002(2002) and ASTM C469/C469M-2014(2014), respectively.

A tailor-designed apparatus was used to monitor the change of temperature during the hydration of concrete (as shown in Figure. 2 a). In this test, the concrete was first cast into a plastic mould (Figure 2) with a dimension of $150 \mathrm{~mm} \times 150 \mathrm{~mm} \times 150 \mathrm{~mm}$. Cotton pads and wooden board were then used to insulate the plastic moulds in order to prevent heat exchange with the outside environment. Followed by this, a temperature probe was embedded into the center of the fresh concrete and the top was then covered by a wooden board. To ensure the sealing of the mould, the whole box was wrapped with tape (as shown in Figure $2 \mathrm{~b}$ ). The temperature during the hydration was then monitored over time.

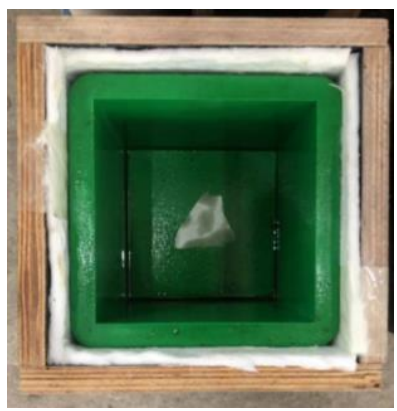

a

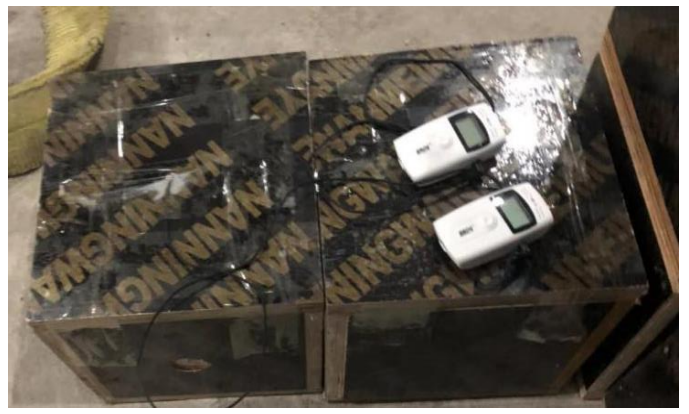

b

Figure 2 Apparatus for measuring the hydration temperature: a: an empty mould; b: sealed moulds within which the samples are being tested

\subsection{Direct Pullout Test}

The bond behavior between reinforcing bar and concrete was tested using a direct pullout test according to ACI 440.3 R-04 (ACI 2004). In this study, six groups of pullout specimens were tested as shown in Table 4. However, it should be noted that except the MPC-GFRP and PC-GFRP groups, only fresh water was employed as mixing water. Three samples were tested in each group 
and the average value was reported. Thus, a total of 24 samples were tested for bond behavior.

Table 4 Design of pullout experiment

\begin{tabular}{ccc}
\hline Concrete Type & Reinforcing bar & Mixing water \\
\hline \multirow{2}{*}{ MPC } & Steel & Freshwater \\
& BFRP & Freshwater \\
& GFRP & Freshwater \\
& GFRP & Seawater \\
& Steel & Freshwater \\
PC & BFRP & Freshwater \\
& GFRP & Freshwater \\
& GFRP & Seawater \\
\hline
\end{tabular}

The reinforcing bars with a designed bond length of $65 \mathrm{~mm}$ was cast into a $200 \mathrm{~mm}$ cube. This embedded length was employed to meet the requirement that the bond length should be at least five times the diameter of the bar (i.e. 5x 13mm) (Baena et al., 2009). Using this bond length, it is anticipated that the bond stress reached at the failure stage should be close to the actual local bond stress (Xie et al., 2018). To ensure the designed bond length can be achieved, PVC tubes were pre-fixed at the designated location on the reinforcing bar before casting concrete. Additionally, to avoid debonding between the bar and the PVC tube, sponge tape was inserted between the tube and the bar to ensure that there was no gap in-between. However, due to the poor shear strength of FRP bars, the FRP bars cannot be directly connected to the anchor for the tensile test. Therefore, the loading ends of the FRP bar were embedded in a $200 \mathrm{~mm}$ long steel tube filled with expansive cement. The schematic drawing of the sample is shown in Figure 3 a). Figures 3 b) and $3 \mathrm{c}$ ) present the pictures taken at the different stages of sample preparation and manufacture. The final manufactured specimens are shown in Figure $3 \mathrm{~d}$ ). After casting, all the samples were moved to a curing room under a standard curing condition (i.e. $20 \pm 2^{\circ} \mathrm{C}$ temperature and $95 \%$ relative humidity). After 24 hours, all the specimens were demoulded, marked, and then stored in the curing room until 28 days.

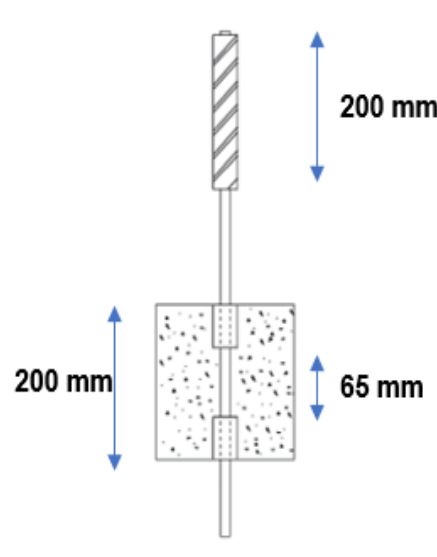

(a)

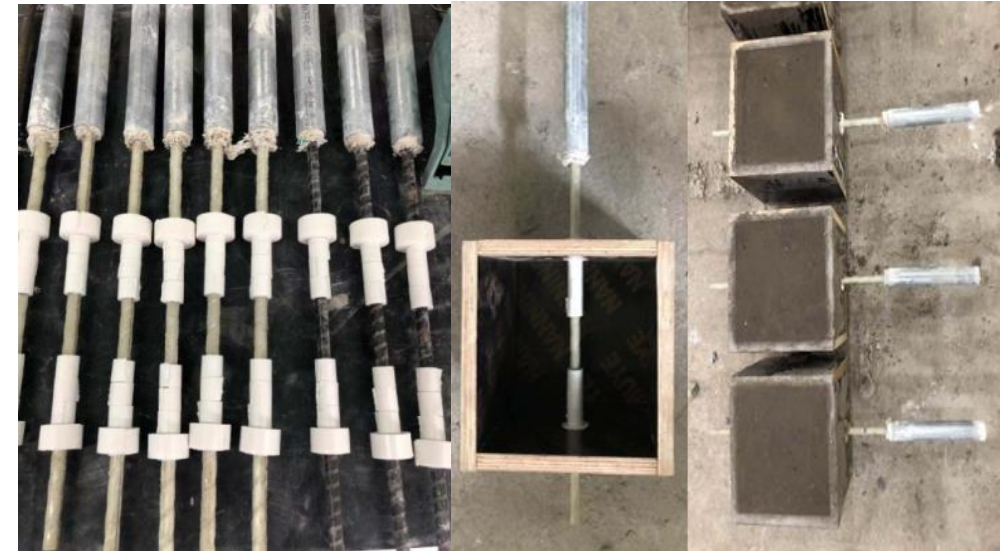

(b) (c)

Figure 3 Sample preparation: a) schematic drawing of the sample; b) preparation of reinforcing 
bars; c) preparation of mould; d) completed samples.

Figure 4 (a) shows a schematic diagram of the pullout test setup. In this test, a $1000 \mathrm{kN}$ universal testing machine with a maximum displacement of $70 \mathrm{~cm}$ was used to carry out the pullout test. The load was applied under a displacement-controlled mode with a displacement rate of $0.02 \mathrm{~mm} / \mathrm{s}$. The magnitude of the load was continuously recorded by the acquisition system every three seconds. To avoid the eccentricity of the specimen during loading, two linearly variable differential transformers (LVDT) were placed vertically at the free end of the bar to measure the free end slip, as shown in Figure 4 (b). The displacement change was continuously recorded by the TDS-540 acquisition system.
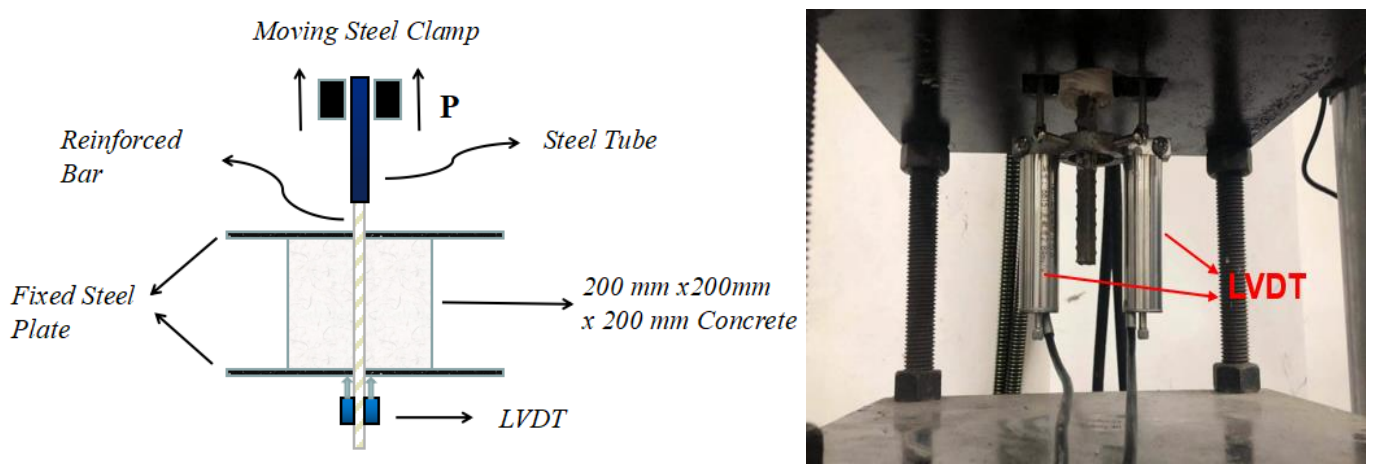

Figure 4 Direct pullout test: (a) schematic diagram; (b) LVDT setup

\section{Result and Discussion}

\subsection{Basic properties of MPC concretes}

The mechanical properties, including compressive strength and elasticity modulus of the MPC and PC concretes, were obtained in accordance with the Chinese standard GB/T50081-2002 and ASTM C469/C469M, respectively, and the results are presented in Table 5. It can be seen that, at the early stage, the compressive strength of the MPC concrete was relatively higher than that of the PC. However, similar compressive strengths were achieved at 28 days which is as expected because the mix design of the PC concrete was established through trials based on similar 28-day compressive strength. On the other hand, the 1-day compressive strength of MPC-seawater concrete was slightly lower than that of the freshwater MPC counterpart, with the former being 35.5 $\mathrm{MPa}$ and the latter being 37.1 MPa. Additionally, from Table 5, it can be noticed that the elasticity modulus of MPC is slightly higher than that of PC, in particular, during the early ages, which could be attributed to the fast strength development nature of MPC concretes.

Table 5 Compressive strength and elasticity modulus of MPC and PC

\begin{tabular}{|c|c|c|c|c|c|c|c|}
\hline \multirow[t]{2}{*}{$\begin{array}{c}\text { Concrete } \\
\text { type }\end{array}$} & \multirow[t]{2}{*}{ Mixing water } & \multicolumn{3}{|c|}{$\begin{array}{l}\text { Compressive } \\
\text { strength/MPa }\end{array}$} & \multicolumn{3}{|c|}{$\begin{array}{c}\text { Elasticity } \\
\text { modulus/GPa }\end{array}$} \\
\hline & & $1 \mathrm{~d}$ & $7 d$ & $28 d$ & $1 \mathrm{~d}$ & $7 d$ & $28 d$ \\
\hline
\end{tabular}




\begin{tabular}{cccccccc}
\hline MPC & Freshwater & 37.1 & 43.8 & 48.0 & 32.8 & 32.3 & 35.6 \\
MPC & Seawater & 35.5 & 44.2 & 48.7 & 31.9 & 34.3 & 37.4 \\
PC & Freshwater & 32.3 & 43.9 & 50.1 & 25.8 & 31.2 & 35.1 \\
PC & Seawater & 32.5 & 40.3 & 47.5 & 26.3 & 29.9 & 33.9 \\
\hline
\end{tabular}

To identify the effect of concrete type and mixing water on the heat generated during hydration, the temperature of the concrete during the early-stage hydration was measured over time and this is depicted in Figure 5. It was found that the temperature of the MPC concrete increased sharply within a short period of time and reached the peak temperature of around $74^{\circ} \mathrm{C}$ after only 40 minutes. However, the temperature of the PC concrete increased relatively slowly and reached the peak temperature (around $47.5^{\circ} \mathrm{C}$ ) at approximately 600 minutes. It should be noted that the temperature profiles of the MPC and PC pastes correlate well with the strength development of their concrete counterparts reported in Table 5. Additionally, seawater showed little effects on the hydration temperature development of MPC concrete, but accelerated the early hydration of the PC concrete.

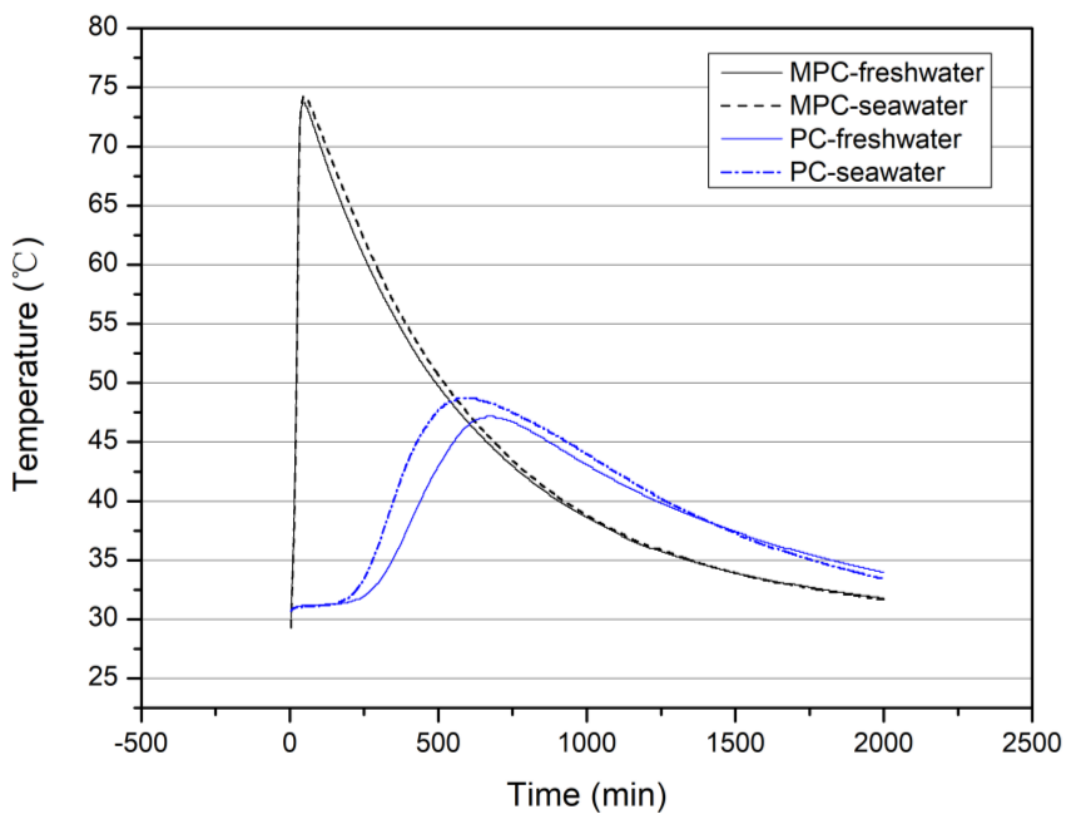

Figure 5 Hydration temperature of MPC and PC concretes

\subsection{Failure modes and bond strength}

Through a series of direct pullout tests, the results of maximum pulling force $\left(\mathrm{F}_{\max }\right)$, slip value $(\delta)$, bond stress $(\tau)$ and failure modes were obtained and these are summarized in Table 5 . It has been reported in the literature that the air void around the interface between reinforcing bar and concrete can influence the bond behavior (Maranan et al., 2015). However, there was no void noticed around the bars during the pullout test based on the observation of the failure pattern of the test specimens. This indicates that all the samples were properly manufactured, meeting the requirements of pullout test. In general, it has been widely agreed that three failure modes could happen in a pullout test, namely, bar pullout from concrete, concrete splitting and bar rupture. In the current experiments, only bar pullout from concrete was observed. This shows that the selected 
development length can avoid concrete splitting (Maranan et al., 2015).

Table 6 Results of pullout test and failure modes

\begin{tabular}{ccccc}
\hline Specimen type & $\mathrm{F}_{\max }(\mathrm{kN})$ & $\delta(\mathrm{mm})$ & $\tau(\mathrm{MPa})$ & Failure modes \\
\hline BFRP-MPC-F & 37.69 & 2.69 & 14.31 & Bar pullout from concrete \\
GFRP-MPC-F & 40.69 & 0.85 & 15.34 & Bar pullout from concrete \\
Steel-MPC-F & 64.11 & 0.77 & 24.16 & Bar pullout from concrete \\
GFRP-MPC-S & 46.30 & 0.57 & 17.45 & Bar pullout from concrete \\
BFRP-PC-F & 24.84 & 3.96 & 9.47 & Bar pullout from concrete \\
GFRP-PC-F & 32.70 & 0.67 & 12.33 & Bar pullout from concrete \\
Steel-PC-F & 64.55 & 0.58 & 24.33 & Bar pullout from concrete \\
GFRP-PC-S & 28.33 & 6.71 & 10.68 & Bar pullout from concrete \\
\hline
\end{tabular}

Note: ' $F$ ' and ' $S$ ' represent freshwater and seawater, respectively.

A comparison of the bond strength between different types of concrete specimen is shown in Figure 6. It can be seen that, regardless of the type of cement used, the bond strength between concrete and steel bar is the highest. This is then followed by the GFRP bar and BFRP bar, with the BFRP being the lowest. This finding could be attributed to the high elastic modulus of steel reinforcement (as shown in Table 2) and the crescent ribs on the surface of the steel bar. The crescent ribs can enhance the mechanical interlock between the bar and the concrete when the concrete surrounding the concrete-bar interface was sheared out under tensile load. This is further discussed in the section below. In contrast, the surface of the GFRP bar was treated by sand coating and spiral filament winding, whilst that of the BFRP was only treated by spiral filament winding. It has been widely confirmed that the sand coating on GFRP bars could enhance the bond strength by increasing the mechanical interlock and friction forces between reinforced bars and concrete (Arias et al., 2012; Tang et al., 2008). It is, therefore, no surprise that the bond strength of the GFRP bars is higher than that of the BFRP bars.

In this study, the PC and MPC concretes were designed to develop similar strength at 28 days. Therefore, the effect of concrete strength on bond strength can be ignored. According to Figure 6, it is evident that the type of concrete had no effect on the bond strength of the steel bar. This is because the bond strength between the steel bar and the concrete is mainly determined by the mechanical interlock. The chemical adhesion and the friction at the steel-concrete interface would have little effect on the bond strength. Thus, a similar bond strength was observed in the MPC-steel bar system and PC-steel bar system. However, a significant difference in the bond strength can be noticed from the BFRP and GFRP bars. As can be seen in Figure 6, both the BFRP and GFRP bars showed higher bond strength in MPC concrete than in PC concrete, with a 51.06\% and a $24.42 \%$ increase being achieved for the BFRP and GFRP, respectively. This can be explained by several reasons. Firstly, as reported by Dong et al. (2018) and Guo et al. (2018), the bond strength can be decreased by the degradation of the FRP bar under the alkaline environment of PC. It was found that the debonding can occur between the fiber and the resin in the alkaline environment of PC, leading to the reduction in both the shear resistance and the bond strength of FRP bar. In addition, the fiber/matrix interface could also be attacked by the high $\mathrm{pH}$ of the PC. In contrast, MPC has a relatively lower $\mathrm{pH}$ value (around $\mathrm{pH}$ 8-9 depending upon the M/P) than that 
of PC (pH 12-13). This weakly alkaline environment of MPC may result in less degradation of the FRP bar. Hence, a strong MPC-FRP interface can be maintained, contributing to higher bond strengths. Secondly, the unreacted magnesia left in the composite might have increased the abrasion resistance of MPC (Wang, 2006). This could be anticipated that the friction forces at the MPC-reinforcing bars' interface was increased. However, even though these assumptions sound applaudable, further research is still needed before these could be verified. Furthermore, it can be noticed that the difference in the bond strength between the BFRP and the GFRP is reduced when MPC is used to replace PC. This may imply that the properties of concrete could have played a more important role than the surface treatment for improving the bond strength.

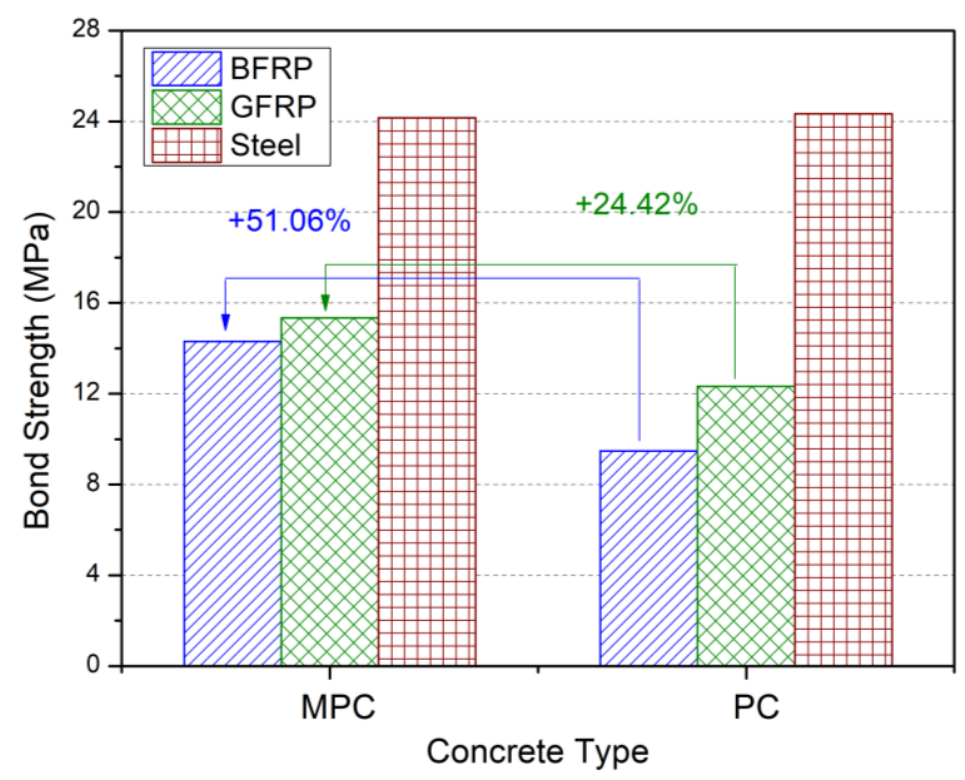

Figure 6 Comparison of the bond strength of different types of specimens

To identify the effect of mixing water on the bond strength of FRP bars, artificial seawater was used to replace the freshwater in the GFRP matrices and the results are presented in Figure 7. As can be noticed, changing from freshwater to seawater, the bond strength of PC-GFRP decreased by $13.38 \%$. This finding is in good agreement with those reported in the literature. For example, it has been reported that the mechanical properties of the GFRP bar were reduced overtime when the GFRP bar was exposed to salt solutions (Wang et al., 2017, Silva et al., 2014 and Robert et al., 2013). In another study, Liu et al. (2012) investigated the effect of the ocean environment on the durability of the GFRP bar and their results also showed that the mechanical properties of the GFRP bar were decreased with an increase in seawater immersion time. Similar results were also reported by Wang et al. (2018) in which they mentioned that the porosity between the glass fiber and the resin was increased under the seawater environment, leading to a debonding problem. In general, the degradation of the GFRP bar has been attributed to the following two reasons. The first is the degradation of the resin. As exemplified in Guo et al.'s (2018) research, when the FRP was immersed in the simulated pore solution of seawater sea sand normal concrete (SWSSNC) at $60^{\circ} \mathrm{C}$, the resin of FRP was found to be leached out after six-month exposure to the SWSNC environment. The second reason is the destruction of the fiber structure. Because the silicate network of FRP can be gradually dissolved under the alkaline environment of the pore solutions due to the reaction between the silicate in the fiber and the alkaline-ions in the 
pore solution as presented in Eq. 3 and Eq. 4 (Guo et al., 2018). On the other hand, the chemical reaction could also happen between the aluminum/ magnesium in the glass fiber and the alkali and/or chloride ions in the SWSSNC environment, as described in Eq. 5 and Eq. 6 below (Guo et al., 2018).

$\equiv \mathrm{Si}-\mathrm{OR}+\left(\mathrm{H}++\mathrm{OH}^{-}\right) \rightarrow \equiv \mathrm{Si}-\mathrm{OH}+\mathrm{ROH}$

$\equiv \mathrm{Si}-\mathrm{O}-\mathrm{Si} \equiv+\left(\mathrm{R}^{+}+\mathrm{OH}^{-}\right) \rightarrow \equiv \mathrm{Si}-\mathrm{OH}+\mathrm{RO}-\mathrm{Si}$

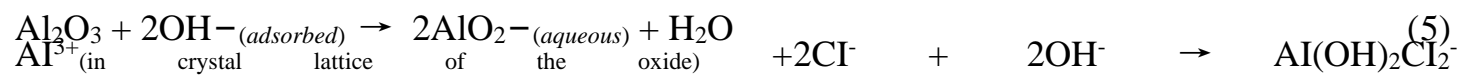
(6)

This, in turn, exacerbated the decrease of the bond strength of GFRP bars embedded in the seawater sea sand concrete. In addition to its influence on the GFRP bar, seawater can also affect the properties of hardened PC concrete, which could then influence the bond strength between the PC-GFRP bar. For example, Xing et al. (2015) reported that the salt content in seawater could reduce the 28-day compressive strength of concrete. Adel et al. (2018) also demonstrated that using seawater in concrete, the 28-day compressive strength was decreased by $7-10 \%$, even though the 7-day compressive strength was slightly increased. A similar trend was also observed in the current study, as shown in Table 5. The increase of early strength might be attributed to the lower porosity because of the accelerated hydration during the early age (Kaushik and Islam, 1995). The reduction in the long-term strength could be due to the sulfate attack on the PC by potassium and magnesium sulfates in seawater (Wegian 2010). The reaction between magnesium sulfate in seawater and calcium hydroxide $\left(\mathrm{Ca}(\mathrm{OH})_{2}\right)$ from PC hydration could produce magnesium hydroxide $\left(\mathrm{Mg}(\mathrm{OH})_{2}\right)$ and gypsum $\left(\mathrm{CaSO}_{4} \cdot 2 \mathrm{H}_{2} \mathrm{O}\right)$, which results in strength loss (Wegian 2010; Adel et al., 2019). Since the magnesium hydroxide is relatively insoluble and its saturated solution is poorly alkaline $(\mathrm{pH}=10.5)$, the stability of the calcium silicate hydrate $(\mathrm{CSH})$ is reduced, thereby converting the $\mathrm{CSH}$ phase to magnesium silicate hydrate (MSH) with no binding properties. Whilst, magnesium hydroxide $\left(\mathrm{Mg}(\mathrm{OH})_{2}\right)$ and gypsum $\left(\mathrm{CaSO}_{4} \cdot 2 \mathrm{H}_{2} \mathrm{O}\right)$ also brings expansion crystallization pressure to concrete and lead strength loss (Al-Amoudi 2002). Additionally, Sergio et al. (2020) assessed the GFRP bond behavior in reinforced seawater concrete and showed that the maximum pullout force and shear strength were slightly lower when tap water was replaced by seawater to mix PC concrete. Therefore, it could be concluded that using seawater as mixing water in PC-based concrete could decrease the bond strength of GFRP. The reduction of bond strength may be attributed to the combined effects of concrete deterioration, FRP bar and resin degradation as well as the weakened concrete-bar interface.

However, in contrast, the bond strength of the MPC-GFRP prepared with seawater was increased by $13.75 \%$ than that with freshwater. This might be caused by the improvement in the MPC properties with seawater as exemplified by Yu et al.' work (2017), in which they found that if the MPC contains some mineral admixtures, the seawater can have a positive impact on compressive strength. In our experiment, the MPC was a commercial product pre-blended with some fly ash. From a microstructure perspective, the weakly alkaline environment of seawater could benefit the reaction of MPC and fly ash, promoting the formation of a much denser structure of the hardened MPC matrix (Yang et al., 2017). Although only a slight increase in compressive strength was observed from the MPC concrete with seawater at 28 days (as shown in Figure 2), a $13.75 \%$ increase in the bond strength was achieved, which could be attributed to the enhanced GFRP-MPC interface. However, to fully understand what has happened at the microscale level, 
further studies are still needed, which is beyond the scope of this paper.

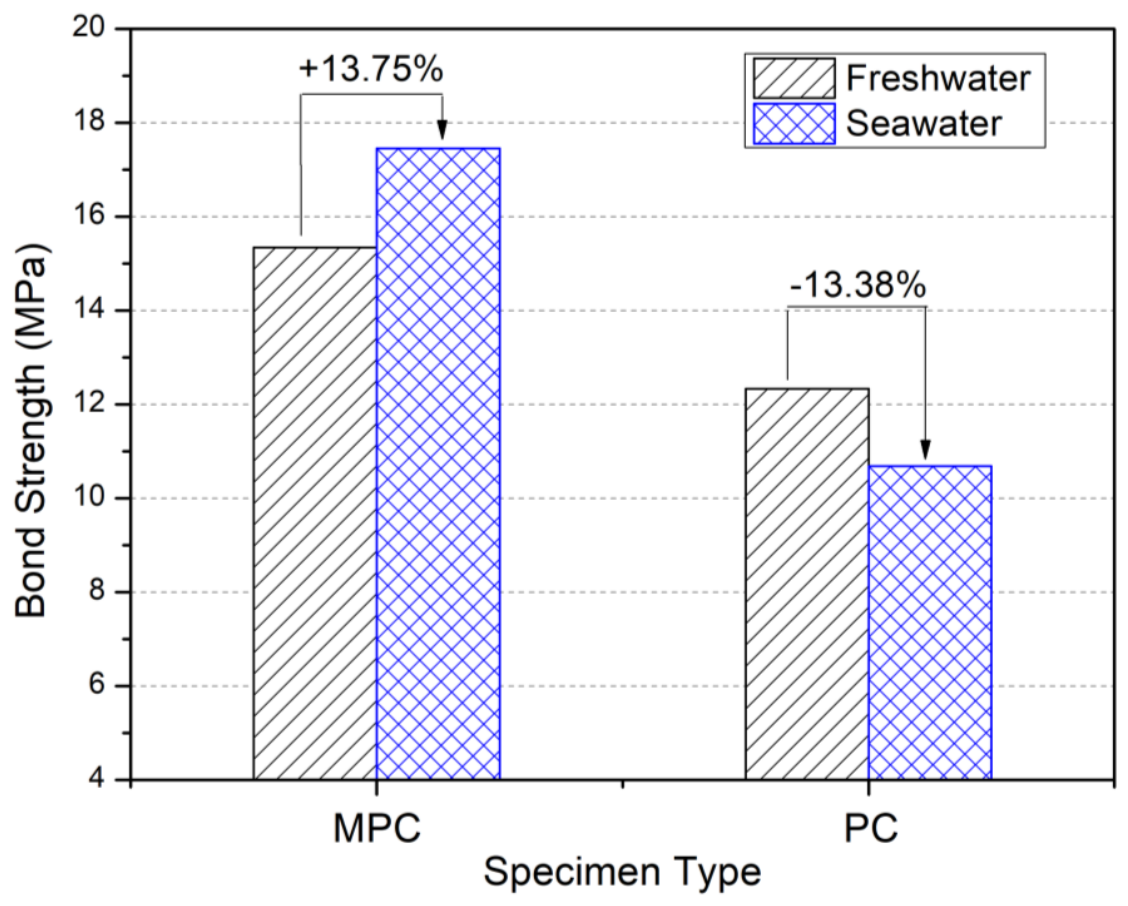

Figure 7 Effect of mixing water on bond strength

\subsection{Interface damage analysis}

The damage caused to the interface between the reinforcing bar and the concrete after the pullout tests is shown in Figure 8. In general, the failure modes fall into the following three categories, namely: (i) debonding from the bar/concrete interface with the partial rupture of FRP ribs and the partial peeling of resin (as shown in Figures 8(a)- PC and 8(b)- PC); (ii) debonding from the bar/concrete interface with a complete rupture of FRP ribs and complete peeling of resin (Figures 8(a)-MPC and 8(b)-MPC); and (iii) debonding from the bar/concrete interface with the failure of concrete (Figure 8(c)).

It should be noted that the failure mode (iii) only happened to the steel bar, irrespective of the type of concrete. This could presumably be attributed to the high elasticity modulus and crescent rib of the steel reinforcement, leading to a higher mechanical interlock and an increased friction force. This hypothesis can be further confirmed by the observation, as shown in Figure 8(c), that the concrete adhered to the surface of the steel bar was sheared out with some residue concrete left between the ribs. On the other hand, between the two FRP bars studied, the interface damage caused to the GFRP was more severe than that of BFRP. As shown in Figure 8(a), part of the ribs could still be seen at the BFRP interface, but hardly seen at the GFRP interface (Figure 8(b)). Additionally, in MPC specimens, not only the color of the interface was brighter, indicating more resin shedding, the ribs were also more seriously damaged than that in the PC specimens. All these observations are consistent with the bond strength results shown in Figure 6. It can, thus, be tentatively concluded that replacing PC concrete with MPC concrete can potentially improve the adhesion between FRP bar and concrete. 


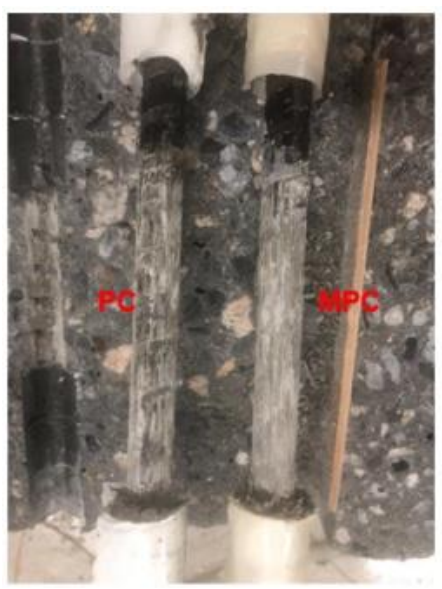

a

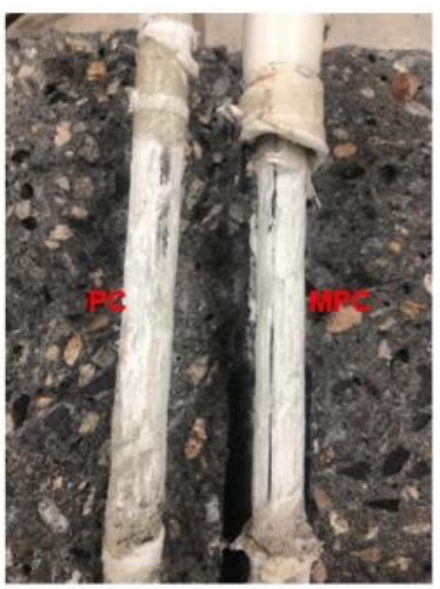

b

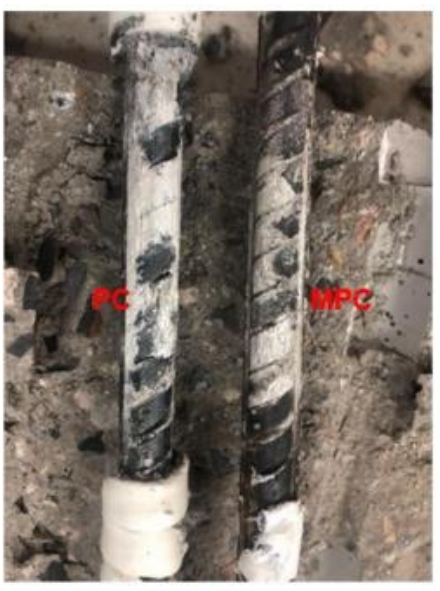

C

Figure 8 Comparison of the interface damage in MPC and PC: a: BFRP bars b: GFRP bars; c: Steel bars

\subsection{Bond stress-slip relationship curve}

There is wide agreement that the bar pullout failure should normally go through three distinct stages in the whole pullout process, namely, the linear, nonlinear, and softening stages. (Maranan et al., 2015; Golafshani et al., 2014). Similarly, three stages were also identified in the current study, as shown in Figure 9. At the initial stage, the bond stress was increased linearly and dramatically with no measurable slip. It is generally believed that the bond stress at this linear stage is mainly determined by the chemical adhesion and mechanical interlock between the bar and the concrete (Maranan et al., 2015). However, a lower stiffness response was observed at the beginning of the curve in the BFRP-PC specimen. This might be due to the surface unevenness of the loaded end of PC concrete when the specimen settle (Maranan et al., 2015). As the load was increased continuously, the curve shifted from linear to nonlinear and then up to the maximum bond stress. At this stage, the mechanical interlock and friction forces mainly controlled the bond stress, and the microcracks were initiated in the concrete around the bars. After the peak bond stress (i.e. bond strength) being reached, the curve started to decline until the bar was pulled out from the concrete. At this stage, the mechanical interlock was decreased, and the friction forces started to control the bond mechanism. In addition, the 'wedging effect' may also occur at this stage because of the better mechanical properties of concrete (Sérgio et al., 2020). In the following sections, the effects of different reinforcing bars (steel, BFRP and GFRP bars), concretes (PC and MPC) and mixing water (freshwater and seawater) on the bond behavior between reinforcing bar and concrete are further analyzed and discussed in great detail.

\subsubsection{Effect of reinforcing bar}

According to Figure 9 and Table 6, Points A-D are all denoted as 'completed linear' stages, with bond stresses of up to $19 \mathrm{MPa}(\mathrm{A}$ and $\mathrm{C}$ ) and $9 \mathrm{MPa}$ (B and D). This indicates that the steel bar had a higher chemical adhesion and mechanical interlock with concrete than that of the FRP bars because the steel bar has a higher elastic modulus (i.e. about $210 \mathrm{GPa}$ ). On the other hand, whilst the BFRP and GFRP bars had similar chemical adhesion and mechanical interlock, these 
are lower than that of the steel bar, which could be due to their lower, but similar elastic moduli, which are $50 \mathrm{GPa}$ and $54 \mathrm{GPa}$, respectively. In addition, the good surface treatment of the steel bar could also have improved the bond stiffness during the linear stage. Furthermore, the concrete-steel bar had the highest bond strength, but the lowest peak slip value, which is followed by the concrete-GFRP bar. The concrete-BFRP bar had the smallest bond strength, but the highest peak slip value. The reason for these differences could be attributed to the lower deformation and the crescent ribs of steel bar, which provides the highest mechanical interlock and friction forces. The larger bond strength of the GFRP bar than that of the BFRP bar could be due to the sand coating treatment on the GFRP bar surface, resulting in a higher friction force. Thus, the higher elastic modulus and better surface treatment of reinforcing bars could be the main reason that led to the larger bond strength and smaller peak slip value.

However, at the descending stage, the bond stress between the concrete-steel bar decreased rapidly. It was noticed that the concrete around the steel bar was sheared out and destroyed at this stage during the experiment, which might explain the quick reduction in the mechanical interlock and friction forces. In addition, the fast drop of the bond stress between the concrete-BFRP bar was also observed, but the failure mechanism seems different from that of the concrete-steel bar. In the former case, it was mainly dominated by the rupture of the ribs and the peeling-off of the resin. It should be noted that a more gradual descending curve can be noted from the concrete-GFRP bar, which could be primarily due to the slight surface damage and the sand-coating treatment.

It is interesting to note that the bond stress-slip curve of the BFRP bar experienced a periodic fluctuation, which could be related to the rib spacing as proposed by Baena M et al. (2009). However, this observation was not seen in the bond stress-slip curves of the GFRP bar and the steel bar. This is because the rib spacing of GFRP exceeds the measurement range. As for steel bars, the ribs cannot provide effective friction forces, resulting in the rupture of concrete around the bar surface.

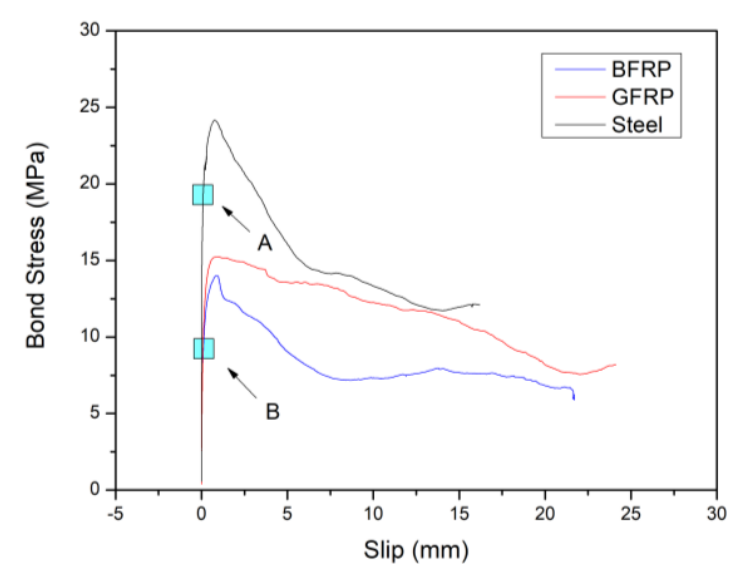

(a) MPC

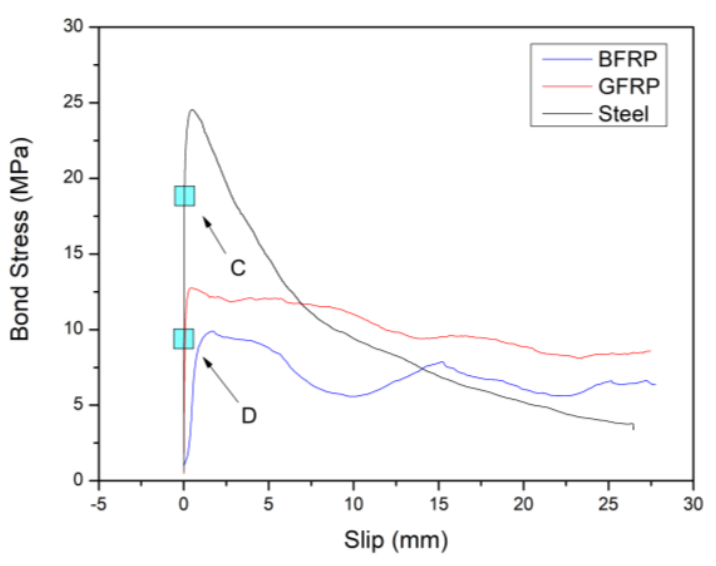

(b) $\mathrm{PC}$

Figure 9 Bond stress-slip relationship curves: (a) MPC-freshwater; (b) PC-freshwater

\subsubsection{Effect of concrete}

From Figure 9, it can be seen that the trends of the curves of steel bars are similar in both MPC and PC concretes, indicating that the type of concrete has no effect on the bond behavior of 
steel bars. In the case of the GFRP bar, the only difference is that the bond strength of the MPC-GFRP bar was larger than that of the PC-GFRP bar, which was around $15 \mathrm{MPa}$ and 12.5 $\mathrm{MPa}$, respectively. Additionally, the comparison between the bond stress-slip curves of MPC-BFRP and PC-BFRP showed that whilst a higher bond strength occurred in the MPC concrete, a smaller peak slip value was also recorded. This could be attributed to the higher elastic modulus of the MPC concrete as compared to that of the PC concrete. At the descending stage, the bond stress dropped rapidly due to the reduction of friction forces. This is because the ribs and the resin at the BFRP surface were ruptured and peeled off more severely in the MPC concrete, as shown in Figure 8 (a). The periodic fluctuation of the MPC-BFRP was not as obvious as that of the PC-BFRP, which could again be caused by the more severe damage occurred at the interface.

\subsubsection{Effect of mixing water}

Figure 10 illustrates the effect of mixing water on the bond stress-slip relationship of GFRP specimens. In the case of PC-GFRP specimens, the bond strength was decreased by $13.38 \%$ when the concrete was mixed with seawater, and the peak slip was substantially increased from $0.67 \mathrm{~mm}$ to $6.71 \mathrm{~mm}$. The mechanical interlock between the PC concrete and the GFRP was also decreased, which could be attributed to the reduced compressive strength of the PC seawater concrete. This, in turn, led to a higher slip value at the nonlinear ascend stage. However, in the case of the MPC-GFRP specimens, the bond strength was increased with seawater, and the descending curve became slightly steeper. This could be resulted from the improved MPC-GFRP interface due to the chemical reaction occurred between the MPC concrete and the seawater, as the alkaline environment of seawater may promote the hydration of MPC (Yang et al., 2017) and consequently benefit the MPC-GFRP interface.

In addition, the inset of Figure 10 shows the enlarged view of the early stage bond stress-slip relationship. It is interesting to note that, regardless of the type of concrete, the slope of the curves with seawater (Line 1) is higher than that of the freshwater (Line 2) at the linear stage. Since the slope indicates the bond stiffness of the concrete-bar interface, the different slope between Line 1 and Line 2 implies that seawater could improve the resistance of the interface to shear deformation. In general, it can be concluded that using seawater as mixing water in MPC concrete can enhance the bond behavior of the MPC-GFRP bar 


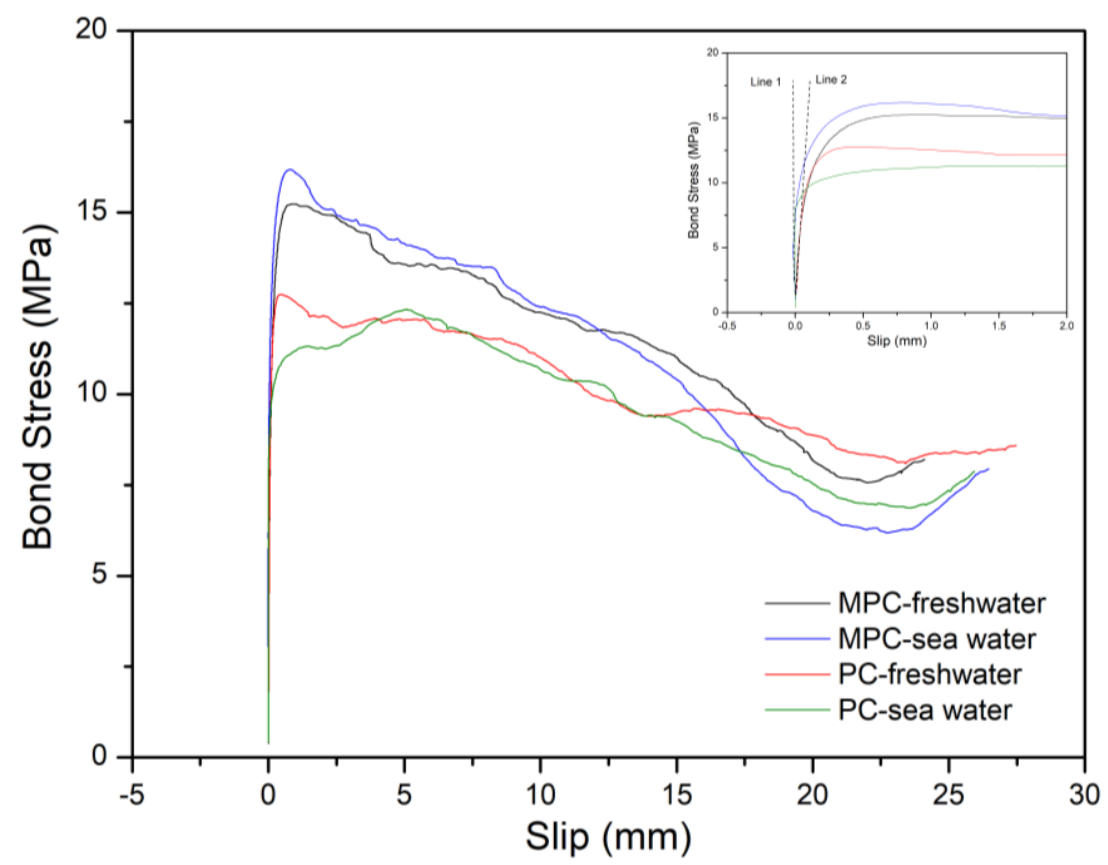

Figure 10 Bond stress-slip relationship between GFRP bars and concretes manufactured with freshwater and seawater

\subsection{Models for describing the bond behavior}

In the literature, several analytical models have been developed by researchers to describe the bond behavior of FRP bar in concrete, including the BPE model, mBPE model, Malvar's model and CMR model (Yan et al., 2016). Among these, the mBPE model, which is modified from the BPE model, has showed to be able to precisely describe the three stages of pullout test (Yan et al., 2016). In addition, the CMR model has been considered as the most reliable model to describe the ascending stage of the bond stress-slip curve (Maranan et al., 2015). Thus, in this study, both the mBPE model and CMR model were adopted as constitutive analytical models to simulate the bond behavior of different reinforcing bars. The ascending stage of the curve at the serviceability state level (i.e. the ascending stage of bond stress-slip curve) simulated by these two models are then compared and presented below.

It should be highlighted that the mBPE model can be used to describe all the three stages of the pullout process. The expression formulas are depicted in Equations (7)-(9) as follows:

$$
\begin{aligned}
& \frac{\tau}{\tau_{\mathrm{b}}}=\left(\frac{\mathrm{s}}{s_{b}}\right)^{\alpha}, 0 \leq \mathrm{s} \leq s_{b} \\
& \frac{\tau}{\tau_{\mathrm{b}}}=1-\mathrm{p}\left(\frac{\mathrm{s}}{s_{b}}-1\right), \quad s_{\mathrm{b}} \leq \mathrm{s} \leq s_{3} \\
& \tau=\tau_{3}, \mathrm{~s} \geq s_{3}
\end{aligned}
$$

Where $\tau=$ bond stress (MPa); s =slip at $\tau(\mathrm{mm}) ; \tau_{\mathrm{b}}=$ peak bond stress (MPa); $\mathrm{s}_{b}=$ slip at peak 
bond stress (mm). $\alpha$ and $\mathrm{p}$ are the parameters to be obtained from the experimental data.

The CMR model, which was originally developed by Cosenza et al. (1997) through the modification of the ascending stage of BEP, can be used to depict the ascending behavior of the bond stress-slip curve more reliably (Maranan et al., 2015). The Equation is given by

$$
\tau=\tau_{\mathrm{b}} \cdot\left(1-\mathrm{e}^{-\mathrm{s} / \mathrm{s}_{\mathrm{r}}}\right)^{\beta}
$$

Where $\tau$ and $\mathrm{s}$ represent the bond stress and the slip at $\tau$, respectively; $\tau_{\mathrm{b}}=$ peak bond strength(MPa); $s_{\mathrm{r}}$ and $\beta$ are the parameters to be obtained from the curve fitting of experimental data.

For each type of concrete-GFRP system, both the mBPE and CMR models were applied to simulate the experimental results. The parameters of the models obtained from the experimental data are presented in Table 7. The comparison of the PC-GFRP bond stress-slip curves obtained from the experimental results with those from the proposed models are shown in Figure 11. It is evident that at the ascending stage, the CMR model matches the experimental data better than the mBPE model, indicating that the CMR model is more suitable for predicting the bond behavior at the serviceability state level. At the descending stage, a similar trend can be observed between the experimental curve of the seawater mix and that predicted from the mBPE model. A little fluctuation of the experimental curve might have been caused by the ribs and the sand coating of GFRP. However, in the freshwater mix, the descending stage of the experimental curve is different from that of the mBPE model in that the real bond stress dropped faster than that predicted from the model. In addition, it can be noticed that the fluctuation of the experimental data of the PC freshwater concrete is higher than that of the seawater concrete. This could be attributed to the higher bond strength between GFRP bars and PC freshwater concrete.
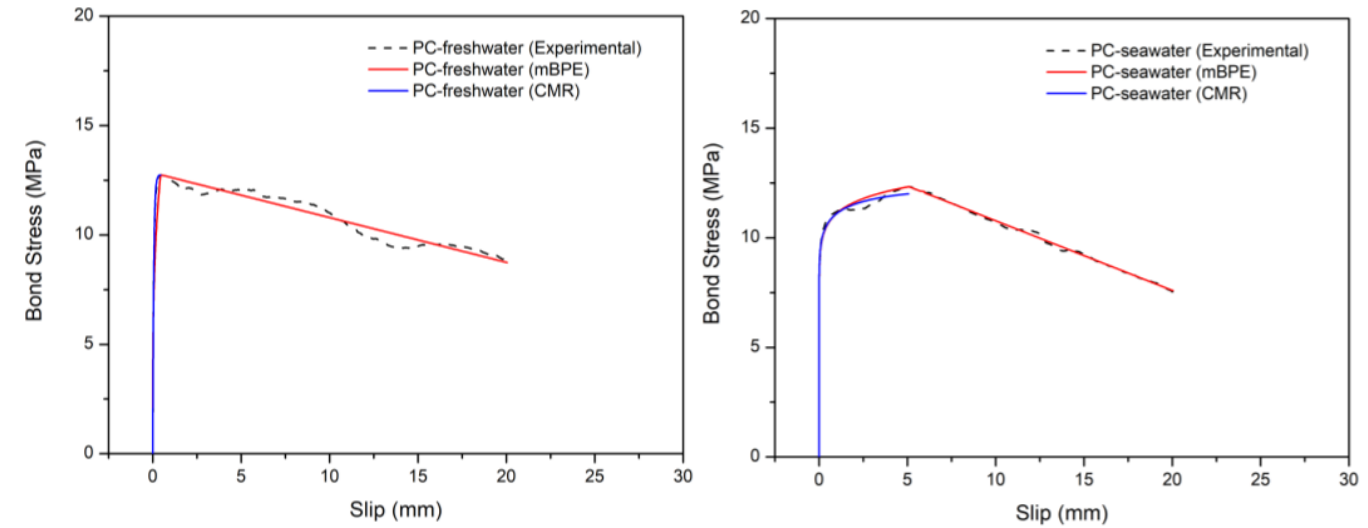

Figure 11 GFRP bond stress-slip curves from the experimental results and the proposed models: (a) PC-fresh water; (b) PC-seawater

Figure 12 shows the comparison between the MPC-GFRP bond stress-slip curves obtained from the experimental results and those predicted from the models. It can be seen that the results predicted by the two theoretical models show good agreement with the test results. However, some differences still can be noticed at the descending stage of the curves. The fluctuation of experiment data from the MPC seawater concrete is higher than that from the MPC freshwater concrete. The MPC-GFRP specimen made from seawater has a higher bond stress than MPC with freshwater. It seems that the fluctuation of the experiment curve at the descending stage is related to the bond stress of GFRP bars regardless of the type of concrete and mixing water used. 
However, further studies are still needed to verify this observation. Nonetheless, it can be concluded that, in general, both the mBPE model and the CMR model can be used to predict the bond behavior of the MPC-GFRP bar.

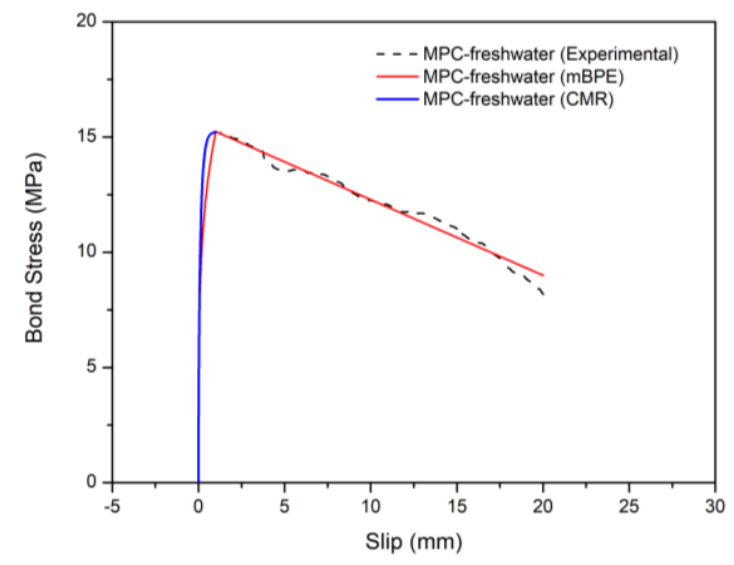

(a)

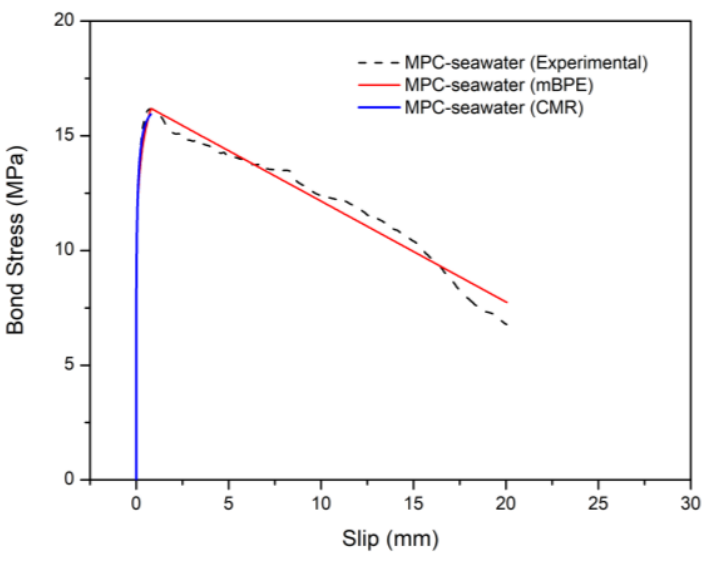

(b)

Figure 12 GFRP bond stress-slip curves of the experimental results and predicted from the models: (a) MPC-fresh water; (b) MPC-seawater

Table 7 Bond Slip Parameters of the mBPE and CMR models

\begin{tabular}{|c|c|c|c|c|}
\hline \multirow{2}{*}{ Specimen (GFRP) } & \multicolumn{2}{|c|}{ mBPE } & \multicolumn{2}{|c|}{ CMR } \\
\hline & $\alpha$ & $\mathrm{p}$ & $\mathrm{s}_{\mathrm{r}}$ & $\beta$ \\
\hline PC-fresh water & 0.2834 & 0.0072 & 0.0589 & 0.9752 \\
\hline PC-seawater & 0.0638 & 0.1306 & 4.7587 & 0.0630 \\
\hline MPC-fresh water & 0.2476 & 0.0217 & 0.1603 & 0.5651 \\
\hline MPC-seawater & 0.1321 & 0.0216 & 0.3137 & 0.1888 \\
\hline
\end{tabular}

\section{Conclusions}

In this study, the influence of MPC and seawater on the bond behavior of three different reinforcing bars, namely, GFRP, BFRP and steel bars, were studied through a direct pullout test. Based on the experimental and modelling investigation carried out in this study, the following conclusions can be drawn:

1. Using MPC to replace PC concrete does not have an obvious effect on the bond strength of steel bars. However, using MPC can improve the bond strength of BFRP and GFRP bars by $51.06 \%$ and $24.42 \%$, respectively, compared with that of PC. This indicates that using MPC can result in higher bond strength between FRP bars and surrounding concrete materials because the interface adhesion is enhanced.

2. The bond strength of the PC-GFRP bar was decreased by $13.38 \%$ when seawater was used to replace freshwater as mixing water. It was found that the reduction in bond behavior comes from the combined effects of concrete deterioration, the degradation of FRP bar and resin as well as the weakened concrete-bar interface. 
3. The bond strength of the MPC-GFRP bar was increased by $13.75 \%$ when seawater was used to replace freshwater as mixing water. The weakly alkaline environment of seawater may have benefited the reaction of MPC and fly ash, promoting the formation of a much denser structure of hardened MPC matrix, thereby enhancing the bond strength.

4. The failure modes of the MPC and PC specimens with steel bars were similar in that the debonding from the bar/concrete interface occurred due to the concrete failure. On the other hand, between the two FRP bars studied, the interface damage of GFRP was more severe than that of BFRP.

5. Both the mBEP and CMR models can be used to simulate the bond behavior of the MPC-GFRP systems with seawater. The predicted bond stress-slip curves show good agreement with the experimental data.

\section{Acknowledgments}

This research was supported by the Natural Science Foundation of China (51678149), Key Research Project by Department of Education of Guangdong Province, China (2018KZDXM068) and the Innovation Group Scheme supported by the Department of Education of Guangdong Province (2019KCXTD013). All these financial supports are gratefully acknowledged.

\section{References}

ACI 440.03R-04 (2004) Guide test methods for FRPs for reinforcing or strengthening concrete structures.

Adel Y, Usama E, Prannoy S, et al. (2018) Fresh and hardened properties of seawater-mixed concrete. Construction and Building Materials 190: 276 - 286.

Al-Amoudi OSB (2002) Attack on plain and blended cements exposed to aggressive sulfate environments. Cement and Concrete Composites 24(3-4): 305-316.

Arias JPM, Vasquez A and Escobar MM (2012) Use of sand coating to improve bonding between GFRP bars and concrete. Journal of Composite Materials 46(18): 2271 - 2278.

ASTM C469/469M-2014 (2014) Standard test method for static modulus of elasticity and poison' s ratio of concrete in compression.

ASTM D1141-98 (2013) Standard Practice for the Preparation of Substitute Ocean Water.

Baena M, Torres L, Turon A, et al. (2009) Experimental study of bond behavior between concrete and FRP bars using a pullout test. Composites Part A Applied Science and Manufacturing 40b(8): 784-797.

Cosenza E, Manfredi G and Realfonzo R (1997) Behavior and modeling of bond of FRP rebars to concrete. Journal of Composite for Construction 1(2): 40-51.

Dong ZQ, Wu G, Zhao XL, et al. (2018) Long-Term Bond Durability of Fiber-Reinforced. Journal of Composites for Construction 22(5): 04018042.

Fan S and Chen B (2015) Experimental research of water stability of magnesium alumina phosphate 
cements mortar. Construction and Building Materials 94: 164 - 171.

GB/T 50081-2002 (2002) Standard for test method of mechanical properties on ordinary concrete.

Golafshani EM, Rahai A and Sebt MH (2014) Bond behavior of steel and GFRP bars in self-compacting concrete. Construction and Building Materials 61: 230-240.

Guo F, Al-Saadi S, Raman RKS, et al. (2018) Durability of fiber reinforced polymer (FRP) in simulated seawater sea sand concrete (swssc) environment. Corrosion Science 141: 1-13.

Kaushik SK and IsIam S (1995) Suitability of sea water for mixing structural concrete exposed to a marine environment. Cement \& Concrete Composites 17(3): 177-185.

Li Y and Chen B (2013) Factors that affect the properties of magnesium phosphate cement. Construction and Building Materials 47: 977-983.

Liu N and Chen B (2016) Experimental research on magnesium phosphate cements containing alumina. Construction and Building Materials 121: 354-360.

Liu X, Wang X, Liu A, et al. (2012) Research progress in durability of GFRP Bars in Marine Construction. Advances in Science and Technology of Water Resources 32(3): 86-89.

Ma H, Xu B and Li Z (2014) Magnesium potassium phosphate cement paste: degree of reaction, porosity and pore structure. Cement and Concrete Research 65: 96-104.

Maranan G, Manalo A, Karunasena K, et al. (2015) Bond stress-slip behavior: case of GFRP bars in geopolymer concrete. Journal of Materials in Civil Engineering 27(1): 04014116.1-04014116.9.

Robert M and Benmokrane B (2013) Combined effects of saline solution and moist concrete on long-term durability of GFRP reinforcing bars. Construction and Building Materials 38(1): 274-284.

Sérgio S, Nelson F, Emanuel P, et al. (2020) Assessment of GFRP bond behavior for the design of sustainable reinforced seawater concrete structures. Construction and Building Materials 231: 117277 1-17.

Silva MAG, Fonseca BSD and Biscaia H (2014) On estimates of durability of FRP based on accelerated tests. Construction and Building Materials 116(9): 377-387.

Tang WC, Lo TY and Balendran RV (2008) Bond performance of polystyrene aggregate concrete (PAC) reinforced with glass fibre-reinforced polymer (GFRP) bars. Building and Environment 43(1): 98 $-107$.

Wang HT (2006) Study on high performance magnesium phosphate cement based materials. PhD Thesis. Chongqin University, China. (in Chinese).

Wang L, Li W, Chen S, et al. (2018) Effect of sea water soaking on the bonding properties of FRP bars-coral concrete. Acta Materiae Compositae Sinica 35(12): 3458-3465 (in Chinese).

Wang Z, Zhao XL, Xian G, et al. (2017) Long-term durability of basalt-and glass-fibre reinforced polymer(BFRP/GFRP) bar in seawater and sea sand concrete environment. Construction and Building Materials 139: 467-489.

Wegain FM (2010) Effect of seawater for mixing and curing on structural concrete. He IES Journal Part A: Civil \& Structural Engineering 3(4): 235-243.

Xiao J, Qiang C, Nanni A, et al. (2017) Use of sea-sand and seawater in concrete construction: current status and future opportunities. Construction and Building Materials 155: 1101-1111.

Xie TY, Mohamed Ali MS, Visintin P et al. (2018) Partial Interaction Model of Flexural Behavior of PVA Fiber - Reinforced Concrete Beams with GFRP Bars. Journal of Composite for Construction 22(5): 04018043.

Xing L, Xue R and Cao X (2015) Performance of concrete with sea sand and sea water. The Concrete 
313(11): 137-141 (in Chinese).

Yan F, Lin ZB and Yang MJ (2016) Bond mechanism and bond strength of GFRP bars to concrete: A review. Composites Part B 98: 56-69.

Yang J, Tang Q, Wu Q, et al. (2017) The effect of seawater curing on properties of magnesium potassium phosphate cement. Construction and Building Materials 141: 470-478.

Yu C, Wu Q and Yang J (2017) Effect of seawater for mixing on properties of potassium magnesium phosphate cement paste. Construction and Building Materials 155: 217-227. 